\title{
The New Mode Based on Theory-Practice-Competition Three-in-One Pattern
}

\author{
Chang-ming Liu ${ }^{1,2^{*}}$, Zhi-gang $\mathrm{Wang}^{3}$, Zhen $\mathrm{Yu}^{4}$ \\ ${ }^{1}$ School of Machinery and Automation, Wuhan University of Science and Technology, Wuhan, China \\ ${ }^{2}$ The State Key Laboratory of Refractories and Metallurgy, Wuhan University of Science and Technology, Wuhan, \\ China \\ ${ }^{3}$ Key Laboratory of Metallurgical Equipment and Control Technology of Ministry of Education, Wuhan University \\ of Science and Technology, Wuhan, China \\ ${ }^{4}$ Hubei Key Laboratory of Mechanical Transmission and Manufacturing Engineering, Wuhan University of Science \\ and Technology, Wuhan, China \\ Email: liuchangming@wust.edu.cn
}

\begin{abstract}
The traditional undergraduate education of the teacher centered mode has not been able to meet the social high-end requirement. The auxiliary teaching virtual instrument technology was introduced as the "three-in-one" mode in the electric drive control program. Focusing on the studentcentered classroom atmosphere, the teacher carried out the teaching and implementation around the current business needs for college student's occupation. At the same time, the extracurricular science and technology competitions were integrated into the class teaching. By means of "do", the textbook knowledge would be transformed into practice of "live" knowledge and the two aspects of knowledge and practical ability of the students were promoted. At last, the innovation ability, practice ability and knowledge master's degree of the students were improved obviously, which laid a good foundation for students to be familiar with their future work.
\end{abstract}

Keywords: three-in-one pattern, classroom teaching, reform, electric drive control.

\section{Introduction}

Paying attention to dissemination and creation of knowledge, talent training and scientific research are three major functions of universities (Chen Xinjun, Tian Siquan, Qian Weiguo \& Sha Feng, 2019). Under the new situation, mission of university teachers is not only to spread knowledge, but also to create knowledge (Ke Jiangfeng, 2019), (Yan Weiying, 2018). At present, Chinese economy is in critical period of industrial restructuring and transformation. In order to meet the needs of domestic and international competition, the traditional primary industry enterprises require more and more in production automation. The practitioners who are mainly from college have gradually shifted from the requirements of traditional knowledge and education to the requirements of high standards for comprehensive quality of knowledge and practical ability, especially for the compound talents (Gao hong, Wu Sheng, Tong Cenghan, Ma Kangmu, Han Bo \& Zheng Jialin, 2015), (Liu Lili, 2015), (Wang Zhihui \& Liu Qingping, 2017). Actually, real knowledge is not acquired through mere rote learning, but recreated by those who pursue it (Sun Yan, Gao Lu, Ma Lixiang, Li Dawei, Fan Wenke \& Li Wensheng, 2019). Therefore, the new teaching method reform arises at the historic moment to adapt to this new situation. In the opinions of the ministry of education on improving the quality of higher education, it is pointed out that "curriculum construction and reform are the core to improve the quality of teaching, and the curriculum system and teaching content should be reformed according to the requirements of technical fields, professional posts (groups) and the relevant vocational qualification standards." (Zeng Shaoxiao, Zhou Arong, Lin Shaoling, Zhuang Weijing \& Huang Qun, 2019)

At present, there is a serious disconnection between theory and practice in the traditional higher education teaching process (Cai Wengui \& Huang Aying, 2019), (Li Xiaochen, Zhang Junlong \& Liu Yuhong, 2019), (Guo Hailing, Zhao Yunshan, Liu Zhenzhe \& Xia Chengbai, 2018). In the classroom teaching, the progress of teaching is almost according to the teacher's prepared textbook knowledge, and students are in a passive position in the urgent need to master the practical ability, which seriously 
decreases the quality of teaching and the cultivation of high-end compound talents (Chen Xiaoqing, 2019), (Fang Yushen, 2019), (Tang Haiming, 2019), (Li Wenli, 2018). Oklahoma first adopted the education quality rating and promotion system (Wang Shuang, Li Kejian \& Hu Biying, 2019), and later other states in the United States also adopted the same method. The system established in just a few years plays an increasingly important role in classroom education (Li Xiaochen, Zhang Junlong \& Liu Yuhong, 2019). However, due to the differences between the education system and the national conditions, this method is not applicable in China (Xia Yangyan \& Cheng Jinkuan, 2019), (Zhang Xiaobao, 2019), (Zhao Xin, Chen Qiang \& Yin Xia, 2019). Therefore, it is imperative to reform the teaching mode of traditional higher education, which focuses on classroom and teacher teaching, supplemented by students' acceptance and participation.

Taking the gs5201-3 silicon core pickling machine automatic production line in the course of "mechanical and electrical drive control" taught by the author as an example, this paper attempts to adopt a new teaching mode of "teaching, learning and doing", which guides the contents of skill competition, extracurricular science and technology competition of college students, which obtains good results.

\section{Curriculum Design and Development}

(1) Design and development concept

Through the way of "analyzing the current situation of social demand, on-the-spot investigation of enterprises and joint feedback of schools and enterprises", the post demand of the automation major of electromechanical transmission control can be understood. Teaching progress need further clarify the theoretical mastery goal and practical mastery degree goal of the course of electromechanical transmission control, and construct the traditional classroom teaching system with the cultivation of students' practical ability and comprehensive professional quality as the main line. The project arrangement, which integrates with the new practical teaching system, highlights the knowledge mastering ability, practical ability, innovation and extracurricular science technology competition of college students. Meanwhile, the project needs match with the professional qualification certificate related to the post and constructs the teaching mode of "teaching, learning and doing" three-in-one professional courses, as shown in Figure 1.

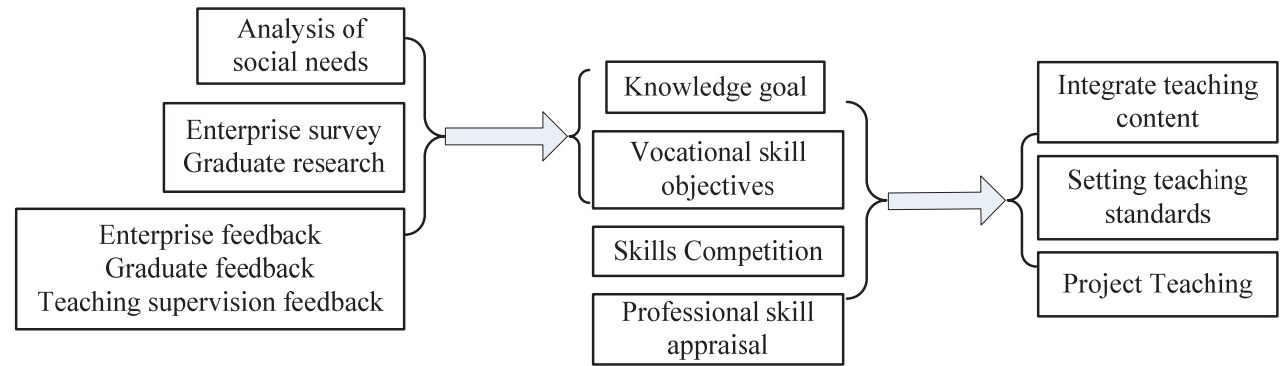

Figure 1. Curriculum development and design roadmap.

In the course of teaching "electromechanical transmission control", through summing up and integrating the current and previous knowledge, such as PLC control technology, sensor and control technology, servo and control technology, motor frequency converter technology, pneumatic transmission technology, mechanical design theory, electrical and electronic technology and other related knowledge, the project implementation such as on-site electrical signal detection, equipment installation and maintenance, PLC ladder program design and other work could be executed directly by students to quickly grasp the basic skills and professional theoretical knowledge needed in the installation/debugging and maintenance of the automation production line in the process of project implementation. The above training strategies could cultivate the basic professional ability of college students engaged in the development, installation and maintenance of automation system/equipment. In order to simulate the environment of the industrial site as much as possible to be real-life, the cultivation norms of 
professional ethics and professionalism should also be integrated into the project implementation and learning process. It is necessary for students to form the professional ethics consciousness of college students' devotion to work, rigorous and solid manner, good at cooperation, and to realize the comprehensive improvement of practical ability, comprehensive application ability of professional knowledge and sustainable development ability.

(2) Design and development ideas

The reform idea is based on the post demand of enterprises, extracurricular science and technology competition rules, and professional qualification standards. The teaching mode is constructed based on the industrial project process, and takes the professional ability of the post demand of enterprises as the training goal. During teaching progress, the professional theoretical learning, practical operation training and professional quality are organically integrated. Afterwards, the automatic production line operation process is designed and integrated as the teaching direction. Tasks are assigned and teaching is implemented based on the assessment of automatic production line. Finally establish a diversified assessment and evaluation system based on the assessment standards of extracurricular science and technology competition, and professional standards, which is shown in Figure 2.

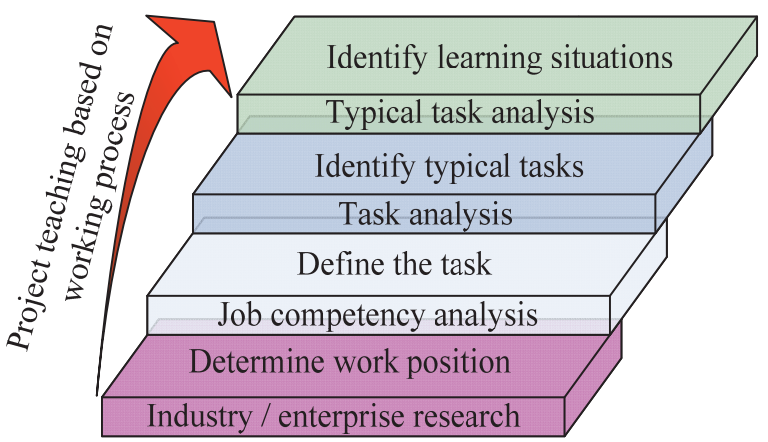

Figure 2. Curriculum design and development ideas.

\section{The Design and Implementation of Teaching Mode}

(1) Implementation of teaching content

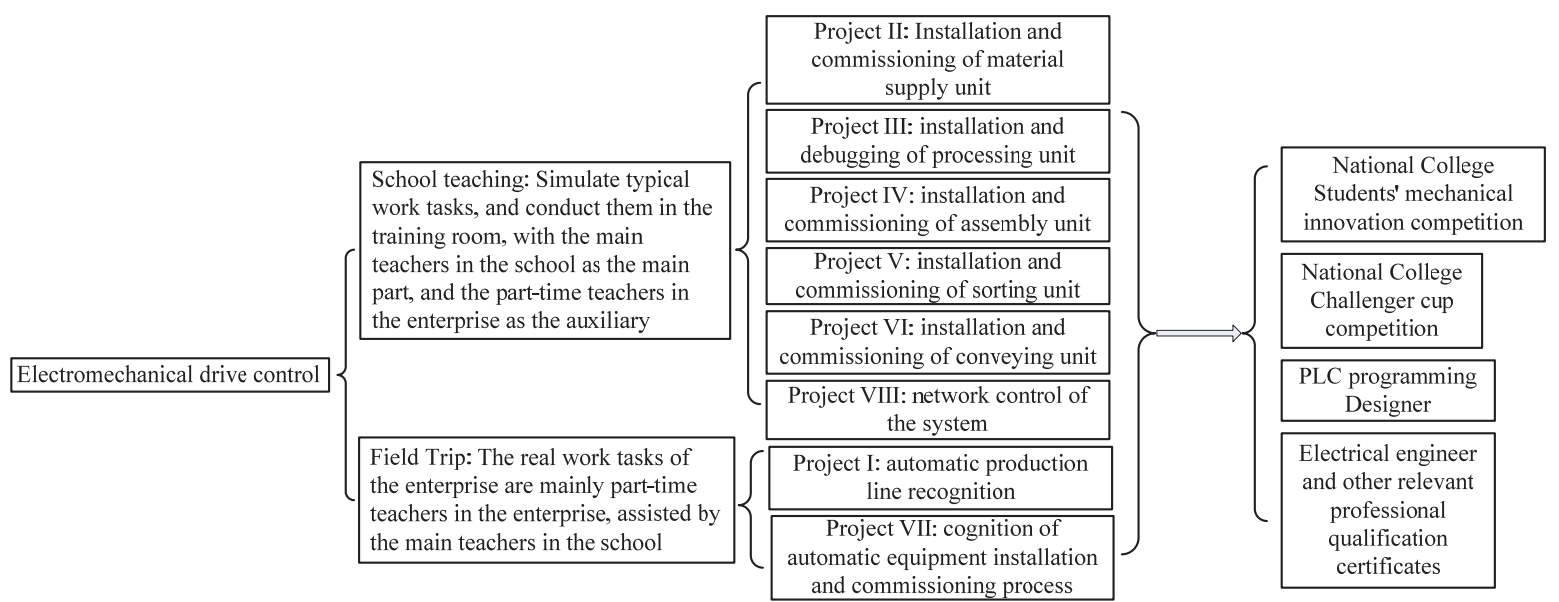

Figure 3. Teaching content implementation.

Based on gs5201-3 silicon core pickling machine automatic production line as the teaching carrier, and virtual instrument as auxiliary means of classroom teaching, the course of mechanical and electrical drive control aims at the ability cultivation of electric control signal detection, equipment installation 
and debugging, PLC ladder diagram program design and other aspects through the decomposition of work tasks and the evaluation of professional ability with the principle of "teaching in doing and learning in doing". The whole course content is divided into 8 sub modules. In the implementation process of the project, each sub module is subdivided into 14 learning scenes, each learning scene has several on-site work tasks. In this way, classroom teaching and on-site teaching are carried out alternately, forming a project-based teaching concept based on the cross integration of professional knowledge, practical ability and professional quality. The specific implementation process is shown in Figure 3.

According to the cognitive ability of college students in the learning process, the arrangement of teaching content will be from simple to complex. Combined with the standards and requirements of professional qualification, the teaching method will be dominated by the on-site work process based on the virtual instrument assisted understanding, which could cultivate the professional ability of college students. At the same time, the extracurricular scientific and technological competition tasks of college students will be integrated into the classroom teaching so as to focus on cultivating students' innovation ability under mastering professional knowledge. In the teaching process, it is also required to pay attention to the training of students' on-site safety awareness in advance, in order to standardize their work awareness, environmental awareness, cost awareness and team spirit. The arrangement of teaching content is shown in Figure 4.

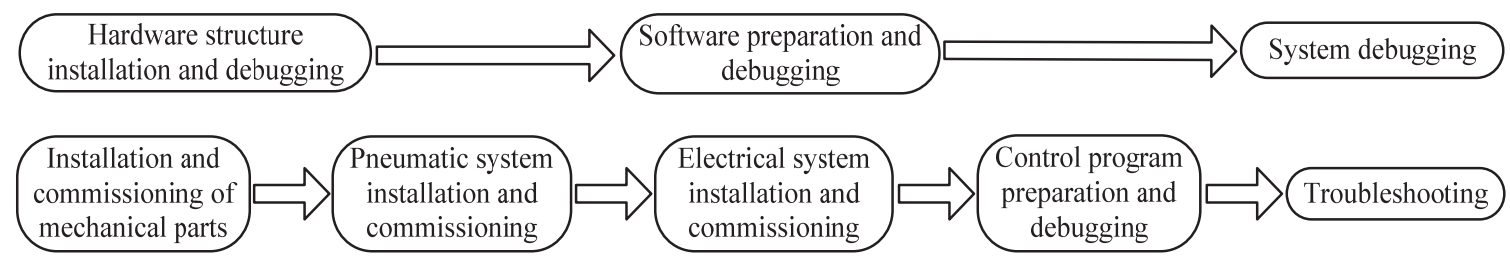

Figure 4. Teaching content arrangement.

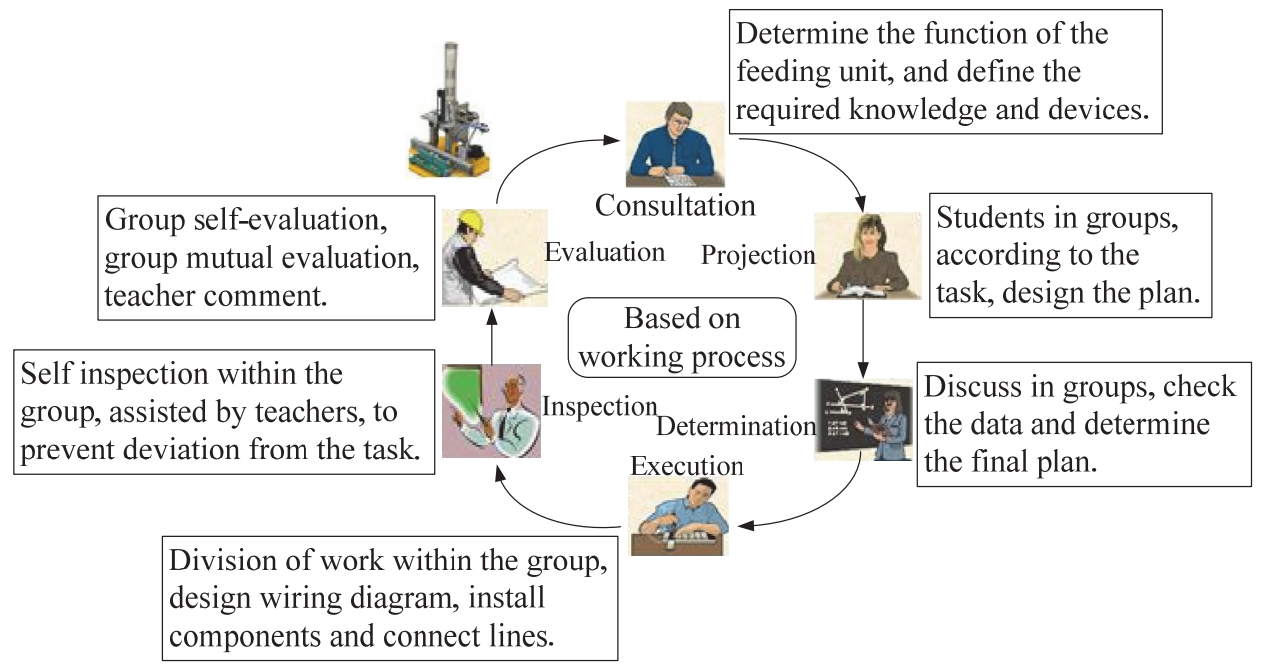

Figure 5. Teaching process implementation.

In the teaching process based on project implementation, the tasks of each subproject are completed according to six steps: consultation, planning, decision-making, implementation, inspection and evaluation. Figure 5 takes the control of polysilicon feeding unit as an example, and integrates PLC control technology, sensor and measurement technology, servo hydraulic control technology, motor frequency conversion technology, pneumatic transmission technology, mechanical design theory, electrical and electronic technology and other related professional knowledge into the project, and submits the implementation results after the task is completed. In the whole process of sub project and sub task implementation, the student's own team is taken as the main body of implementation, and the 
function planning in the process of implementation is constructed by students as following steps: component selection $\rightarrow$ equipment installation $\rightarrow$ I/O distribution of input and output $\rightarrow$ line connection and maintenance $\rightarrow$ programming system debugging. The teacher is the organizer and questioner in the process of project teaching, who gives the necessary guidance to put forward the questions and guide the solutions. It fundamentally stimulates the students' interest in the course and cultivates the students' ability to analyze and solve problems.

(2) Teaching method

In the process of teaching and project implementation, the behavior oriented and situation-oriented teaching methods are adopted to realize the fundamental transformation from "teacher centered learning" to "student centered learning", and from "textbook centered learning" to "work task centered learning". In order to achieve the teaching purpose of taking students as the teaching center and realize the goal of "teaching in doing and learning in doing", according to the individual characteristics of each student and different tasks/contents assigned, the whole class is divided into several groups, and the assignment process is completed by students themselves, not designated by teachers. In the teaching process, different teaching methods, such as project teaching method, combination of teaching and practice method, on-site experience teaching method, heuristic discussion teaching method, reverse thinking analysis method and competition incentive method are tried to be integrated into one, so as to encourage students to complete different tasks. Students can learn independently and cooperatively in the whole process of the project implementation, and change themselves from "ask me to learn" to "I want to learn". Students can complete the learning and understanding of professional knowledge from the implementation of work tasks in the project, and cultivate the ability to analyze problems, solve problems and innovative thinking.

In the process of teaching, the abstract and difficult content are visualized by means of PPT multimedia courseware, animation flash, configuration software, simulation teaching software and other virtual instrument software devices, so as to facilitate students' understanding and mastering, thus improving the quality and effect of classroom teaching.

(3) Establishment of evaluation system

The paper performance evaluation method of "one test and fixed score" has restricted the improvement of the level and quality of contemporary higher education to a large extent. It is easy to form a common adverse situation of high scores and low abilities in the process of student cultivation, which is not conducive to the smooth development of quality education and innovation education advocated at present (Wu Changqu, 2018). According to the rules and standards of extracurricular science and technology innovation competition for college students, the course of mechanical and electrical drive control is assessed separately according to the different division of work/project, and different weights are assigned according to the different project tasks assigned by the students. The final assessment results will be accumulated according to the design weights of each sub project, causing assessment method from "paper" to "process". The assessment opinions would take into account the group members self-assessment, the group mutual assessment and the teacher assessment.

\section{$4 \quad$ Implementation Effect and Conclusion}

Since the implementation of the trinity teaching of "teaching, learning and doing" in the course of electromechanical transmission control, compared with the traditional classroom teaching, there have been fruitful changes, which are shown in Table 1.

In the course of "mechanical and electrical drive control", the trinity teaching mode of "teaching, learning and doing" was integrated into extracurricular science and technology competition, which highlights the important practical links in the process of professional learning. The implementation effects follow the concept of theoretical teaching serving the practical application of enterprises, and achieves the goal of "teaching" and the effect of "learning" in the process of "doing". This method not only improves the teaching effect itself, but also cultivates the ability of students' self-study, selfanalysis and problem-solving ability, and improves their professional quality in the implementation process of project. The implementation of the curriculum reform project is about to or has led to the construction of software and hardware conditions such as teachers, experimental practice, etc. 
Table 1. Effect of "teaching, learning and doing" trinity teaching method pre and post implementation.

\begin{tabular}{|c|c|c|}
\hline Item & Pre-implementation & Post- implementation \\
\hline Curriculum & $\begin{array}{l}\text { Based on theoretical knowledge } \\
\text { and verified by experiment. }\end{array}$ & $\begin{array}{l}\text { Theory and practice are synchronized, mainly including } \\
\text { productive, technological, design and innovative contents. }\end{array}$ \\
\hline Teaching form & $\begin{array}{l}\text { Teachers are the center and } \\
\text { they grant. Students passively } \\
\text { accept. }\end{array}$ & $\begin{array}{l}\text { Students are the center and the main body of practical learning. } \\
\text { Teachers are the response of existence, playing a guiding role. }\end{array}$ \\
\hline Teaching goal & $\begin{array}{l}\text { Focus on theoretical cognition } \\
\text { and standard knowledge. }\end{array}$ & $\begin{array}{l}\text { Theory cognition and behavior are realized together, focus on the } \\
\text { comprehensive ability. }\end{array}$ \\
\hline Teacher's effect & $\begin{array}{l}\text { The organizer of teaching and } \\
\text { the disseminator of knowledge. }\end{array}$ & $\begin{array}{l}\text { The organizer of vocational education, the disseminator of } \\
\text { professional knowledge, the demonstrator of professional } \\
\text { operation, the cultivator of professional ability, the resolver of } \\
\text { professional problems and the teacher of professional ethics. }\end{array}$ \\
\hline $\begin{array}{l}\text { Knowledge } \\
\text { impartment }\end{array}$ & $\begin{array}{l}\text { Teachers tell and demonstrate, } \\
\text { students imitate. }\end{array}$ & $\begin{array}{l}\text { According to students' practice, the teacher gets students' } \\
\text { acceptance ability and gives guidance. }\end{array}$ \\
\hline $\begin{array}{l}\text { Student } \\
\text { participation }\end{array}$ & $\begin{array}{l}\text { The participation of students is } \\
\text { weak, manifesting as "ask me to } \\
\text { learn ". }\end{array}$ & $\begin{array}{l}\text { Students are active and participate strongly, manifesting as "I } \\
\text { want to learn". }\end{array}$ \\
\hline Quality control & $\begin{array}{l}\text { Final theory examination, single } \\
\text { quality control mode. }\end{array}$ & $\begin{array}{l}\text { Focus on learning performance of students in ordinary times, } \\
\text { various quality control mode. }\end{array}$ \\
\hline
\end{tabular}

Acknowledgments. The research is funded by provincial teaching research project of colleges and universities in Hubei province (2016236), the Higher Education Teaching Reformation Project of Hubei Province of China (2008190), education and teaching research project of Wuhan university of science and technology (Yjg201609), National Natural Science Foundation of China (51505346) and the Open Foundation of the State Key Laboratory of Refractories and Metallurgy.

Conflicts of interest. The authors declare no conflict of interest.

\section{References}

1. X. J. Chen, S. Q. Tian, W. G. Qian and F. Sha (2019), "Exploration and Practice of Three-in-One Collaborative Innovation of Distant-Water Fishery Discipline Construction, Scientific Research and Talent Training," Higher Agricultural Education, No.4, pp. 62-67.

2. J. F. Ke (2019), "A Research on the Quality of Regular Organization Activity in the Colleges Under the New Circumstances," Journal of Nanping Teachers College, Vol. 38, No.2, pp. 92-96.

3. W. Y. Yan (2018), "Improvement of Teaching Efficiency of Ideological and Political Theory Course in Private Colleges under the New Situation," Journal of Anhui Agricultural University ( Social Sciences), Vol. 27, No.3, pp. $135-140$.

4. H. Gao, S. Wu, C. H. Tong, K. M. Ma, B. Han and J. L. Zheng (2015), "Exploration and practice of the training pattern of compound high-end medical talents-reference from American $\mathrm{MD} / \mathrm{PhD}$ project experience," Shanghai Management Science, No.1, pp. 95-99.

5. L. L. Liu (2015), "The Study on Strategies of Inter-disciplinary High-ranking Russian Talent Cultivation in Hebei Province with the Economic and Trade Cooperation as Background," Value Engineering, No.29, pp. 251253.

6. Z. H. Wang and Q. P. Liu (2017), "Study on Cultivation Model for Characteristics and High-end Interdisciplinary TCM Informatization Talents," Chinese Journal of Information on Traditional Chinese Medicine, Vol. 24, No.8, pp. 9-13.

7. Y. Sun, L. Gao, L. X. Ma, D. W. Li, W. K. Fan and W. S. Li (2019), "Practice of blended teaching in the teaching of systematic anatomy," Chinese Journal of Anatomy, Vol. 42, No.6, pp. 610-612.

8. S. X. Zeng, A. R. Zhou, S. L. Lin, W. J. Zhuang and Q. Huang (2019), "Practice and Exploration of the Work of Micro-lecture in the Examination Reform of College Course-Take the Course "Food Toxicology" as an Example," The Food Industry, Vol. 40, No.1, pp. 269-272. 
9. W. G. Cai and A. Y. Huang (2019), "Inheriting the Excellent Traditional Culture of China is the Common Mission of the Higher Education in Fujian and Taiwan," Journal of Heilongjiang College of Education, Vol. 38, No.8, pp. 10-12.

10. X. C. Li, J. L. Zhang and Y. H. Liu (2019), "Further Discussion on the Theory of Popularization of Higher Education from the Perspective of Traditional Culture," Journal of Shanxi Radio \& Tv University, No.2, pp. 4649.

11. H. L. Guo, Y. S. Zhao, Z. Z. Liu and C. B. Xia (2018), "The Necessity and Value of Traditional Chinese Medicine Culture Implanted in Medical Higher Education in Ethnic Minority Areas," Journal of Baotou Medical College, Vol. 34, No.12, pp. 117-119.

12. X. Q. Chen (2019), "Japanese New Initiative for Reforming Doctoral Education:The Analysis of "Program for Leading Graduate School" and Its Impact on Chinese Doctoral Education," China Higher Education Research, No.8, pp. $47-53$

13. Y. S. Fang (2019), "Developing Tendency of STEM Research Topics and Knowledge Mapping Analysis in 20 Years," Forum on Science and Technology in China, No.8, pp. 161-169.

14. H. M. Tang (2019), "Five Advanced Steps:The Practical Framework for Cross-Border E-commerce Compound Talent Training — from the Perspective of Training Structured Models," Contemporary Continuing Education, Vol. 37, No.2, pp. 39-45.

15. W. L. Li (2018), "Research on the Countermeasures of the Construction of Intellectual Property Service System in Jilin Province," Management \& Technology of SME, No.26, pp. 105-106.

16. S. Wang, K. J. Li and B. Y. Hu (2019), "Child Outcome Measurement Researches in Quality Rating and Improvement System in US and Its Enlightenment," Early Childhood Education, No.6, pp. 43-47.

17. Y. Y. Xia and J. K. Cheng (2019), "Research on the School System of Independent Schools in EnglandBased on the Analysis of the Education (Independent School Standards) Regulations in England," Elementary \& Secondary Schooling Abroad, No.9, pp. 32-40.

18. X. B. Zhang (2019), "The practice and inspiration of interdisciplinary major education in American research universities," Journal of Higher Education Management, Vol. 13, No.5, pp. 92-103.

19. X. Zhao, Q. Chen and X. Yin (2019), "The Development Status and Enlightenment of CIO System in American Universities_-From a Survey on Informationization System of 104 Chinese Research-oriented Universities," Modern Educational Technology, Vol. 29, No.11, pp. 33-38.

20. C. Q. Wu (2018), "The Mechanism and Approaches of Audio-Visual Educa-tion in Promoting the Cultivation of College Students' Creative Quality in the Information Environment," The Science Education Article Cultures, No.11, pp. 35-36. 